\title{
Variance components of combining ability for different morpho-physiological traits for heat tolerance in bread wheat
}

\author{
Amarjeet Kumar*, Swati, N. K. Singh, Birendra Prasad and Anil Kumar \\ Department of Genetics and Plant Breeding, College of Agriculture, G. B. Pant University of Agriculture and \\ Technology, Pantnagar-263145,Udham Singh Nagar, (Uttarakhand) INDIA \\ *Corresponding author. E-mail: amarjeetagriculture@gmail.com.
}

Received: November 5, 2016; Revised received: February 16, 2017; Accepted: July 2, 2017

\begin{abstract}
To estimate the level of heat tolerance for different genotypes of bread wheat with respect to morphological characters under studied grains/spike, grain weight/spike, grain filling duration (duration between the anthesis stage and the physiological maturity), 1000-kernel weight and grain yield/plant for yield. Physiological traits like relative injury (RI \%), chlorophyll content, canopy temperature depression (CTD), were used in present investigation to contribute toward capability of plants to tolerate heat stress of the yield contributing traits during heat stress. The findings of present investigation had clearly explained that influences of environments on morpho physiological characters i.e. grain yield per plant (14886.15) and its attributing traits i.e. spike length (459.7), tillers per plant (622.34), spikelets per spike (278.1), 1000 kernel weight (13262.39), grain weight per spike (177.89) and number of grains per spike (2898.44) in wheat were highly significant and positive. Among the parent and their crosses had handsome amount of variations across the environment. The results of interaction for environments with parents, lines, testers and their crosses with respect to morpho physiological characters in wheat was found significant for some characters while variation was absent for other characters studied. Physiological traits like relative injury per cent, chlorophyll content and CTD were vital parameters to quantify the degree of heat stress to develop tolerant genotypes which is urgent and present need under changing climate scenario.
\end{abstract}

Keywords: Bread wheat, Combining ability, Heat tolerance, Morpho- physiological traits, Variance

\section{INTRODUCTION}

Wheat is one of the premier cereal crops of worldwide importance which is grown under a wide range of climatic conditions the geometric increase in population, increases the demands of wheat in all countries and introducing advanced lines with superior traits especially according to yield and quality, and is a vital issue. The efficiency of breeding program increases by careful assortment of parents and populations capable of producing progeny with desirable trait combinations (Kumar et al. 2015a).One of the important breeding strategies is crossing the good general combining lines for grain yield and selecting transgressive segregants from its resulting segregating generations. Knowledge of general and specific combining abilities (GCA, SCA) influencing yield and its components has become increasingly important forplant breeders in the choice of suitable parents for developing potentialvarieties in wheat (Anwar et al., 2011).Thus, the success of genetic improvement in any character depends on the nature of variability present in the gene pool for that character. Primarily, biological variation presented in the plant population is of three types, viz., phenotypic, genotypic and environmental. The genotypic variance consists of additive, dominance and epistatic components. Knowledge of the genetic association between grain yield and physiological traits can help the breeders to improve the efficiency of selection (Kumar et al., 2015b). The studies on genetic variability in morpho-physiological traits associated with yield under normal as well late sown conditions can be used to increase selection efficiency (Kumar et al., 2016). In most of the studies dealing with temperature response, days to ear emergence or anthesis has been regarded as key diagnostic character as it represents liaison between vegetative and reproductive stages. High temperature stress during the grain filling duration is a major constraint to increase productivity of wheat in the changing climatic scenario (Punia et al., 2011).

\section{MATERIALS AND METHODS}

The present investigation was carried out at Norman E. Borlaug, Crop Research Centre of Govind Ballabh Pant University of Agriculture and Technology, Pantnagar, India. The material was developed through line $\mathrm{x}$ tester mating during Rabi 2013-14 and their progenies were evaluated in the next Rabi season of 2014-15.Thirteen genetically diverse heat tolerance wheat varieties viz.HD3091, DBW90, UP2843, WH1124, HPW211,WH1021, CBW12, MASC6272, JOB666, HD2329, WAXWING, HD2891, HD2961, 
and three testers i.e. HD2967, WH1105, HD3059 were crossed in line $\mathrm{x}$ tester mating design excluding reciprocals. Complete set of $39 \mathrm{~F}_{1} \mathrm{~s}$, 13lines and 3 testers along with 2 standard checks (DPW 621-50, UP 2338) were evaluated in the Randomized Block Design (RBD) with three replications during rabi 2014-15. Each plot consisted of 2 rows of $1 \mathrm{~m}$ length having plant geometry of $20 \mathrm{~cm} \times 10 \mathrm{~cm}$. To estimate the level of heat tolerance for different genotypes with respect to morphological characters such asgrains/ spike, grain weight/spike, grain filling duration (duration between the anthesis stage and the physiological maturity), 1000grain weight, andgrain yield/plant were taken under studied. However, physiological characters contributing to heat tolerance for various genotypes of bread wheat were (i) Canopy temperature depression (CTD) (withhand held infrared thermometer, model AG-42, Tele temp crop, Fullerton CA) was used for instantaneous measurement of canopy minus air temperature as canopy temperature depression at anthesis and 15 days after anthesis at an angle of $30^{\circ}, 50 \mathrm{~cm}$ above the canopy from horizontal and at one meter distance from the edge of the plot end. Data were recorded between 12:00 hrs.to 14:00 hrs. While, (ii) Relative Injury (\%) estimated by following the procedure and formula of Blum and Ebercon (1981): RI $(\%)=\{1-[1-(\mathrm{T} 1 / \mathrm{T} 2) / 1-$ $(\mathrm{C} 1 / \mathrm{C} 2)]\}$ X 100

Where, $\mathrm{T}$ and $\mathrm{C}$ refer to treatment and control, respectively, and 1 and 2 refer to initial and final conductance readings, respectively. Whereas, (iii) chlorophyll content was recorded in the flag leaves, using a self-calibrating SPAD chlorophyll meter (Minolta) and data were recorded at anthesis and 15 days after anthesis.Pooled analysis of variance for combining ability andmean sum of squares was estimated by following the method of Sokal and Rohlf(1969).

\section{RESULTS AND DISCUSSION}

Result of pooled analysis of variance over two environments for different morpho-physiological characters in wheat had clearly showed the significant variance between two environments. Similar results have also been exhibited by treatments used in experiment. However, parents used for line $\times$ tester mating had also significant variance for all the characters studied except days to maturity results at par to each other. On pooling the data of two environments (Table 1),environment and treatment $\times$ environment significant values of mean sum of squares for yield and yield components such asdays to $75 \%$ heading (13325.48 and 3.09), awn length (62.04 and 0.62), tillers per plant(622.34 and 22.69), spikelets per spike (278.1 and 2.22)flag leaf area (11681.87 and 35.24), 1000 grain weight(13262.39 and 32.53), grain yield per plant (14886.15 and 39.65) biological yield per plant(281885.9 and 701.32), harvest index (2715.36 and48.18), grain filling duration (2892.51 and 9.04)as well as important physiological thermo tolerant traits like relative injury percent (1422.85 and 26.32), chlorophyll content at 15 days after anthesis(1163.76 and 29.86), CTD value at anthesis (498.25 and 2.46) and at 15 days after anthesis (120.99 and1.48) were obtained. However, statistically similar results for variation with respect to treatment $\times$ environment interaction were obtained for morpho-physiological characters such as days to maturity, plant height, spike length, peduncle length, grain weight per spike, grains per spikeand chlorophyll content at the time of anthesis. Variation with regard to crosses across the pooled environment exhibited significant results over all the nineteen morpho physiological traits studied. However, the same trends had also been obtained for Lines used in the mating design except days to maturity deserve lack of variation. Pooled analysis of variance for combining ability among 19 characters studied over two environments $\left(\mathrm{E}_{1}\right.$ and $\left.\mathrm{E}_{2}\right)$ in wheat with respect to tester was found significant for days to $75 \%$ heading(32), spike length(0.4), peduncle length (28.19), tillers per plant (51.22), grain yield per plant (58.23), biological yield per plant(315.88), relative injury percent(1820.66), chlorophyll content at anthesis and 15 DAA (39.1 and 73.35) and CTD at anthesis(0.87). While, non- significant variation were observed for traits like days to maturity, plant height, awn length, spikelets per spike, flag leaf area, 1000 grain weight, grain weight per spike, number of grains per spike, harvest index, grain filling duration and CTD at 15 DAA. Variation was computed significantly positive for Line $\times$ Tester for different morphophysiological traits studied in the present investigation, while, non-significant variation was observed for days to maturity, awn length, 1000 grain weight, biological yield per plant, harvest index, grain filling duration, chlorophyll content at anthesis and at 15 DAA. A peculiar result was observed for grain filling duration, the variation was significant for environment, treatment, parent, crosses, and lines along with treatment $\times$ environment, while absent for line $\times$ tester. It indicates that lack of combining ability among lines and tester for this trait. Statistically significant variation was observed for parents vs crosses for traits like days to maturity, awn length, tillers per plant, 1000 grain weight, grain weight per spike, grain yield per plant, biological yield per plant,harvest index, grain filling duration, relative injury percent and CTD at both stages. However, absence of variation was observed for other traits (Table 1). Interaction effect of other source of variation such as parent, line, tester, line $\times$ tester, crosses and parent vs crosses with environment was found significant for grain yield per plant and canopy temperature depression at the time of anthesis except for parent vs crosses vs environment. However, variation was statistically similar for days to $75 \%$ heading, days 


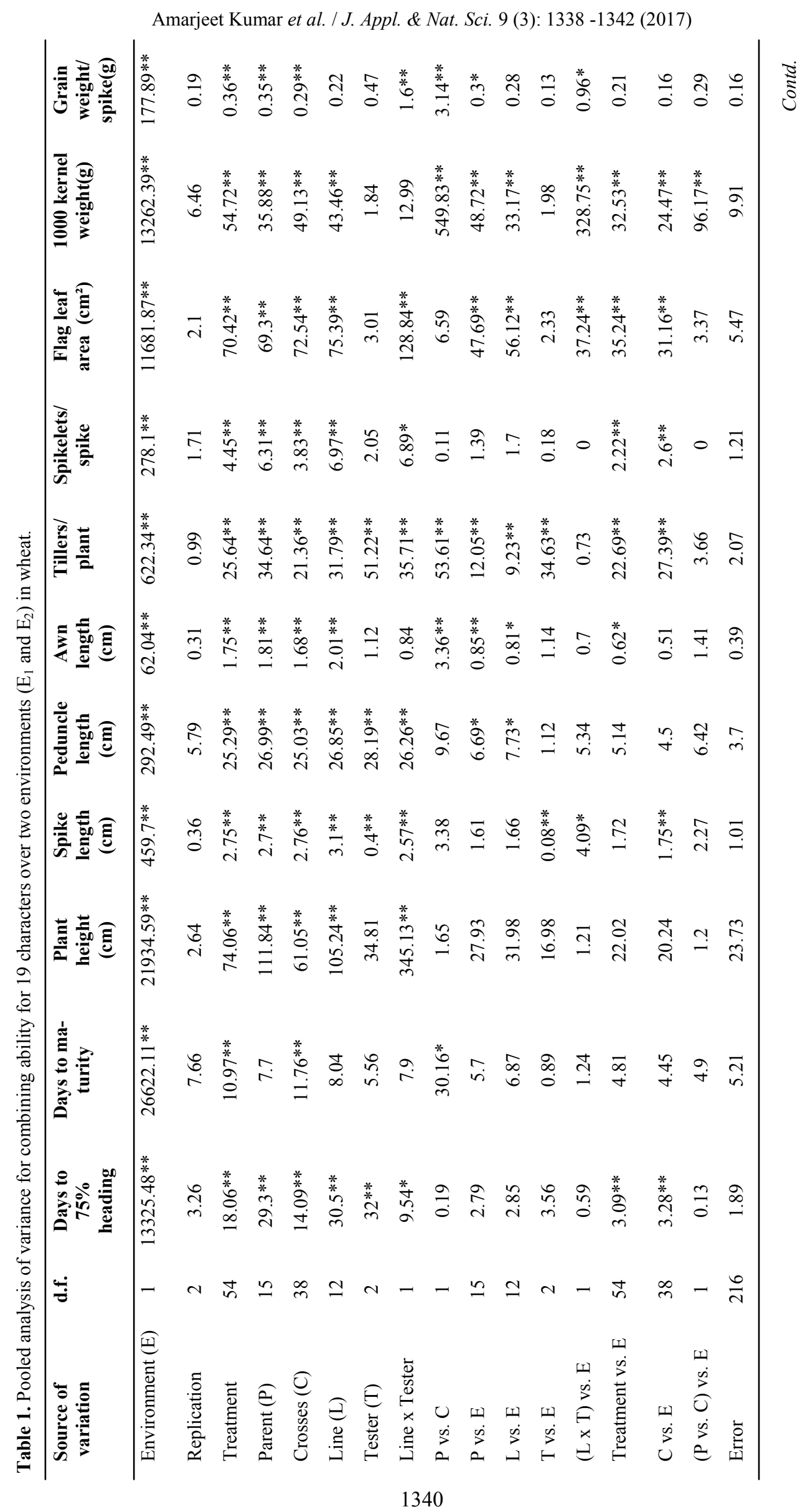




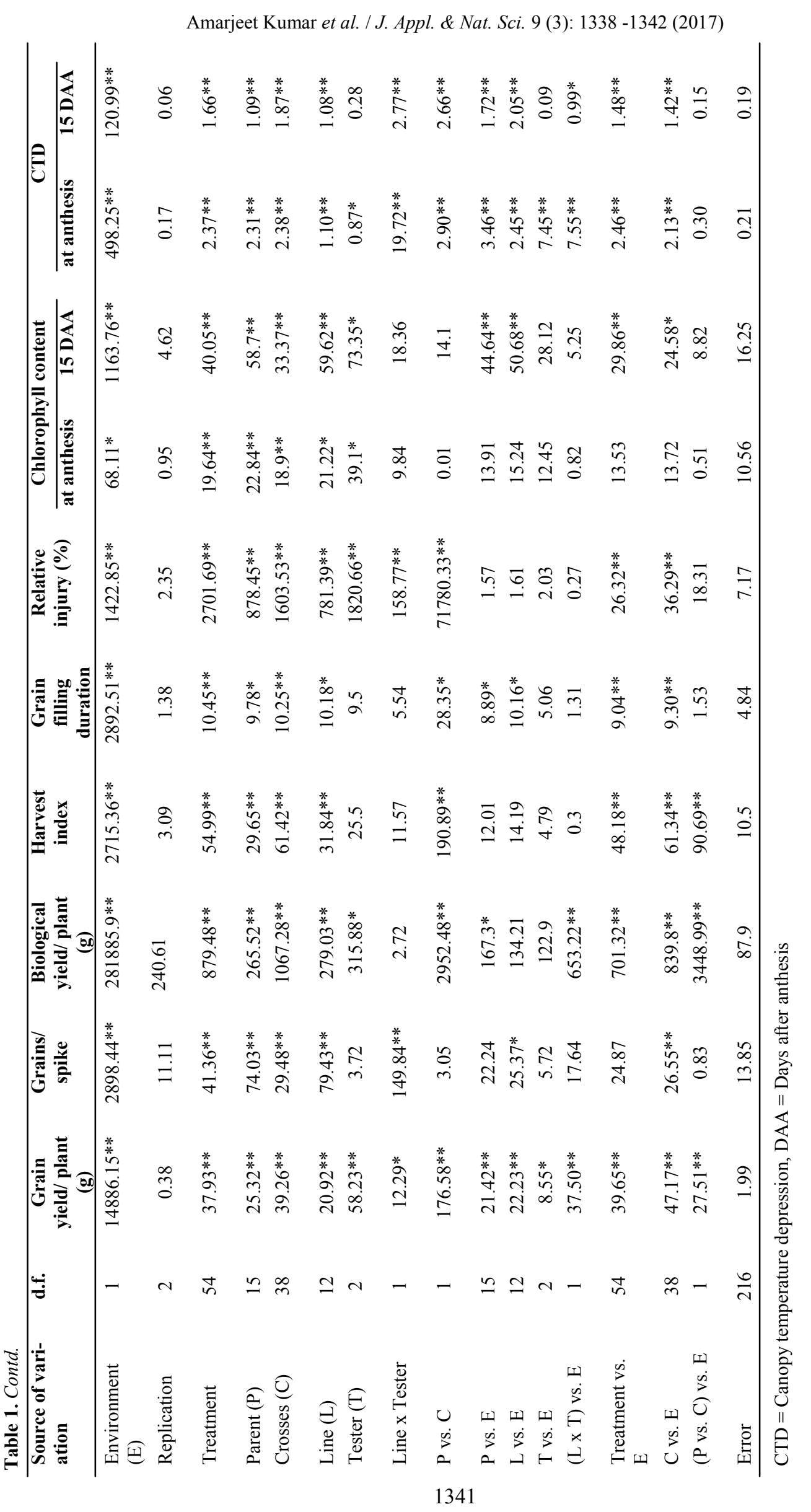


to maturity, plant height, spikelets per spike, relative injury percent and chlorophyll content at anthesis, while, significant variation was observed for days to $75 \%$ heading, spikelets per spike and relative injury percent with respect to crosses vs environment (Table 1).

The utilization of Line $\times$ Tester analysis in wheat breeding is an effective way to find out the genetic bases of grain yield and related components and to identify good general combining parents. Genotypes possessing significant additive gene effects, or GCA variances and non-additive gene effects, or SCA variances (Oettler et al., 2003; Chowdhary et al., 2007; Hammad et al., 2013) for most of the economic traits in wheat can be effectively utilized to make crosses for evolution of new wheat cultivars. The findings of present investigation had clearly explained that influences of environments on morpho physiological characters i.e. yield and its attributing traits in wheat were highly significant and positive. Among the parents and their crosses had handsome amount of variation, which is desirable for crop improvement. The results of interaction for environments with parents, lines, testers and their crosses with respect to morpho physiological characters in wheat was found significant for some characters while variation was absent for other characters studied. These findings have also been supported by Kant et al. (2013) and where he found the larger magnitude of gca compared to gca $\mathrm{x}$ Year mean squares and suggests that interaction effects may be of relatively minor importance for days to heading, ear length, spikelets per ear, grains per ear, grains weight per ear and thousand grain weight. Results were also close confirmation with the observation of Punia et al. (2011), Ram et al. (2014) and Kumar et al. (2015 c and d) in bread wheat who examined twelve lines and four testers in an Line $\mathrm{x}$ Tester mating design, for yield and yield contributing traits under two different environment i.e. timely and late sown condition.

\section{Conclusion}

Analysis of variance exhibited that the mean squares of the treatments for all of 19 characters were significant. This revealed that significant differences were present in the genotypes for the characters studied in both E1andE2.On pooling the data of two environments, environment \& environment $\times$ treatment significant values of squares for yield $(39.65)$ and yield components such as spike length (1.72), tillers per plant (22.69), 1000 grain weight (32.53), biological yield per plant (701.32), harvest index(48.18), days to heading(3.09), flag leaf area (35.24), as well as important thermo tolerant traits like CTD value at anthesis(2.46) and grain filling duration (9.04) were obtained. However, two physiological value 15 days after anthesis(29.86) and relative injury \%(26.32) showed significant values of environment $\times$ treatment interaction. Heat stress substantially affects grain filling duration, its rate, and ultimately grain yield. Timing, duration and intensity of heat stress directly determine its impact on grain yield and yield attributing traits. By using physiological traits like relative injury per cent, chlorophyll content and CTD the adversities of heat stress can be minimized by developing tolerant genotypes which is urgent and present need under changing climate scenario.

\section{REFERENCES}

Anwar, J., Akbar, M., Hussain, M., Asghar, S., Ahmad, J., and Owais,M. (2011). Combining ability estimates for grain yield in wheat.J. Agric. Res., 49(4): 437-445.

Blum, A. and Ebercon, A. (1981). Cell membrane stability as a measure of drought and heat tolerance in wheat. Crop Sci. J., 21: 43-47.

Chowdhary, M.A., Sajad, M. and Ashraf, M. I. (2007).Analysis on combining ability of metric trait in bread wheat (Triticum. aestivum). Journal of Agriculture Research, 45(1): 11-17.

Hammad, G., Kashif, M. Munawar, M. Ijaz, U., Raza, M. M., Saleem M., and Abdullah.(2013). Genetic Analysis of Quantitative Yield Related Traits in Spring Wheat (TriticumaestivumL.). American-Eurasian J. Agric. \& Environ. Sci., 13 (9): 1239-1245

Kant, L., Mahajan, V., Gupta, H.S.(2013).Half diallel analysis of winter, spring, facultative and buitrewheat. Tropical Agri.,90(2):69-78.

Kumar, A., Harshwardhan., Kumar, A. and Prasad, B. (2015a). Heterotic performance of diallel F1 crosses over parents for yield and its contributing traits in bread wheat (Triticum aestivum L.). Journal of Hill Agriculture, 6(1):58-61.

Kumar, A., Harshwardhan., Kumar, A. and Prasad, B. (2015b). Estimation of correlation coefficient for yield and quality parameters of bread wheat under tarai region of Pantnagar. Annals of Plant and Soil Research, 17: 224-228.

Kumar, A., Prasad, B. and Kumar, A.(2015c). Study of variance components of combining ability for yield, its attributing traits in common bread wheat. Elixir Agriculture, 81: 31425-31426

Kumar, A., Harshwardhan, Kumar, A. and Prasad, B. (2015d). Combining ability and gene interaction study for yield, its attributing traits and quality in common wheat. J. Appl. \& Nat. Sci., 7 (2): 927 - 934

Kumar, A. Swati, Jaiswal, J. P. Prasad, B. Bharati, A., and Goel, P. (2016). Characterization of wheat genotypes using Morpho- physiological traits for heat tolerance. Applied Biological Research, 18(2):8-15.

Oettler, G., H. Burger and Melchinger, A. E. (2003).Heterosis and combining ability for grain yield and other agronomic traits in winter triticale. Plant B̈reeding, 122: 318-321.

Punia, S., Shah, M., Ranwha, B.R. M. and Paratap M.(2011). Genetic analysis for high temperature tolerance in bread wheat. Crop A. Society, 19(3): 149-163.

Ram, M., Singh, R. M. and Agrawal, R.K.(2014).Genetic analysis for terminal heat stress in bread Wheat (Triticum aestivum L. em. thell). The Bioscan, 9(2):771776. 